prof. dr hab. inz. Andrzej Grzyb,

dr inz. Piotr Kisielewski

Politechnika Krakowska.

\title{
Metody generowania procesów przypadkowych w dynamice pojazdów
}

\begin{abstract}
$W$ artykule przedstawiono różne metody generowania procesów przypadkowych, szczególnie przydatne $w$ analizie $i$ badaniach symulacyjnych dynamiki pojazdów. Zamieszczono przykłady realizacji procesów przypadkowych z użyciem opisanych metod. Przedstawiono ważne cechy omawianych metod.
\end{abstract}

\section{Wstęp}

W badaniach dynamiki pojazdów lądowych często zachodzi potrzeba generowania procesów przypadkowych, zwłaszcza stacjonarnych i ergodycznych. Do generowania takiego procesu wykorzystywana jest funkcja gęstości widmowej.

$\mathrm{Z}$ uwagi na to, że w literaturze spotykamy różne definicje gęstości widmowych, w rozważaniach przyjęto jej następująca postać, zgodną $\mathrm{z}$ najczęściej stosowaną $\mathrm{w}$ matematyce definicją transformaty Fouriera:

$$
S(\omega)=\int_{-\infty}^{+\infty} K(\tau) e^{-i \omega \tau} d \tau
$$

Przy takiej definicji funkcję autokorelacyjną tego procesu, stanowiącą odwrotną transformatę Fouriera gęstości widmowej, opisuje wzór:

$$
K(\tau)=\frac{1}{2 \pi} \int_{-\infty}^{+\infty} S(\omega) e^{i \omega \tau} d \omega
$$

Na podstawie gęstości widmowej $S_{u}(\omega)$, gdzie $u(t)$ oznacza dowolną funkcję przypadkową, istnieje możliwość generowania realizacji tego procesu stochastycznego.

\section{Opis metody sumy przybliżonej}

Jedną $\mathrm{z}$ przedstawionych tu metod jest zastosowanie wzoru przybliżonego:

$u_{j}=u_{m}+\sum_{k=-p}^{k=p} a_{k} \gamma_{j-k}, \quad j=1,2, \ldots$

gdzie: $u_{m}$ oznacza wartość średnią funkcji $u(t)$, a $u_{j}$ stanowią wartości tej funkcji dyskretyzowane z krokiem $\Delta t$. Wielkości $\gamma_{j}$ są liczbami przypadkowymi o rozkładzie normalnym standaryzowanym (z wartością średnią zero, odchyleniem standardowym równym jeden). Wspólczynniki $a_{k}$ wyznaczane są z gęstości widmowej funkcji $u(t)$ za pomocą wzoru:

$$
a_{-k}=a_{k}=\frac{\Delta t}{\pi} \int_{0}^{\pi / \Delta t} \sqrt{\frac{S_{u}(\omega)}{\Delta t}} \cos (k \Delta t \omega) d \omega
$$

W powyższych wzorach występuje parametr $p$ wyznaczający liczbę $(2 p+1)$ współczynników $a_{k}$ oraz krok dyskretyzacji $\Delta t$. Przy założeniu wymaganej dokładności $\varepsilon$ dobieramy te parametry na podstawie warunku:

$$
\left|1-\frac{1}{\sigma_{u}^{2}} \sum_{k=-p}^{k=p} a_{k}^{2}\right| \leq \varepsilon
$$

w którym:

$$
\sigma_{u}^{2}=K_{u}(0)=\frac{1}{\pi} \int_{0}^{+\infty} S_{u}(\omega) d \omega
$$

Gaussowskie niezależne liczby przypadkowe $\gamma$ można obliczać bezpośrednio $\mathrm{z}$ procedur zawartych $\mathrm{w}$ różnych komputerowych językach lub pakietach programowania, albo pośrednio, wykorzystując łatwo dostępne liczby pseudolosowe $R_{j}$ o rozkładzie kwadratowym z wartością średnią i dyspersją odpowiednio:

$$
m_{R}=1 / 2 \quad \sigma_{R}^{2}=1 / 12
$$

Zgodnie $\mathrm{z}$ twierdzeniem Lindeberga-Levy'ego przy odpowiednio dużym $m$ - można przyjąć:

$$
\gamma=\sqrt{\frac{12}{m}}\left(\sum_{j=1}^{m} R_{j}-\frac{m}{2}\right)
$$

W praktyce przyjmuje się $m=5$ lub $m=12$.

Przedstawiona metoda umożliwia komputerowe modelowanie procesów przypadkowych niezbędnych w analizie dynamicznej pojazdów lądowych. Ważną cechą metody jest to, że kolejne generowane odcinki realizacji omawianych procesów spełniają warunki ciagłości tych realizacji i ich pochodnych.

Poniżej przedstawiono wyniki wybranych symulacji komputerowych. 
Do analizy wykorzystano wyniki pomiarów gęstości widmowych różnych rodzajów dróg kołowych $\mathrm{z}$ pracy [4] przedstawione na rys.1.

Wartości funkcji $\Phi_{h}(\Omega)$ z tego rysunku należy podzielić przez $2 \pi$, aby otrzymać $S_{w}(\lambda)$, przy czym:

$$
\lambda=2 \pi / L
$$

Przykładowy wykres funkcji gęstości widmowej nierówności $w(s)$ drogi thuczniowej przedstawiono na rys. 2. Zmienne $s$ i $\lambda$ są odpowiednikami zmiennych $t \mathrm{i}$ $\omega$ stosowanych powyżej, przy opisie metody generowania.

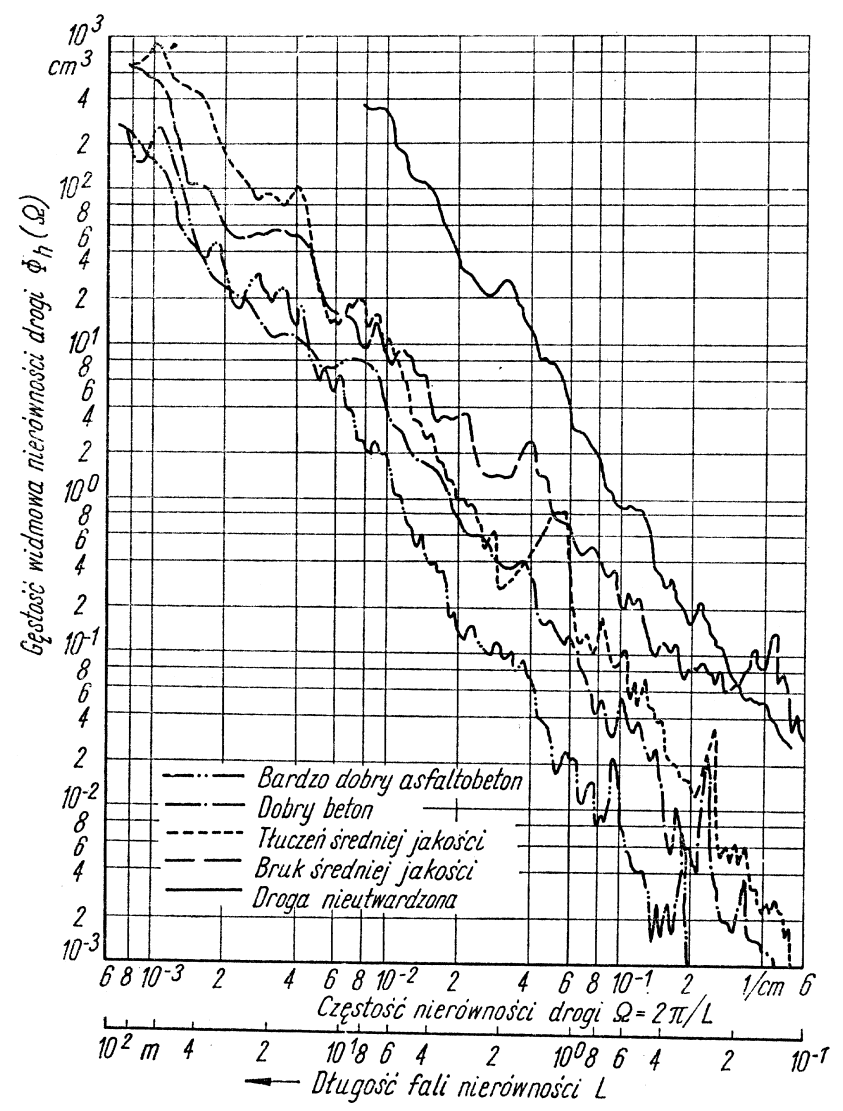

Rys. 1. Gęstość widmowa nierówności różnych rodzajów dróg

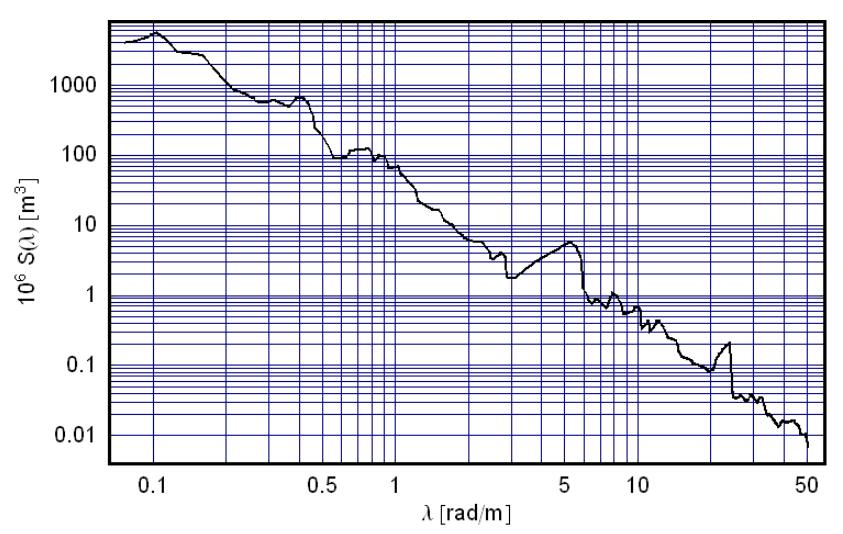

Rys. 2. Funkcja gęstości widmowej nierówności drogi tłuczniowej
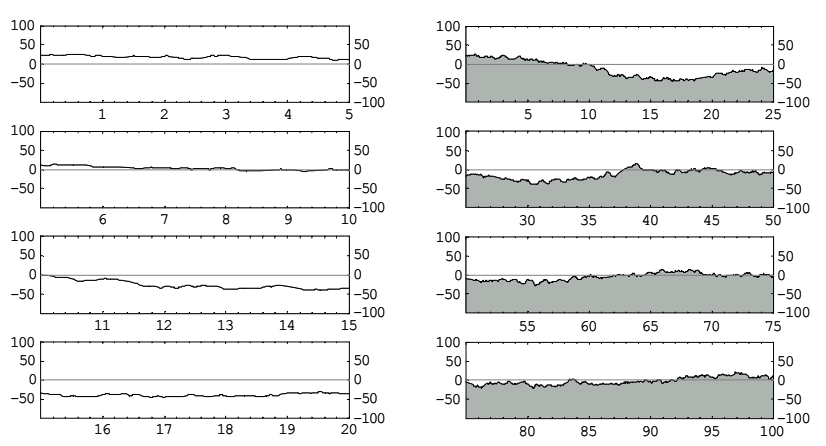

Rys. 3. Droga tłuczniowa średniej jakości
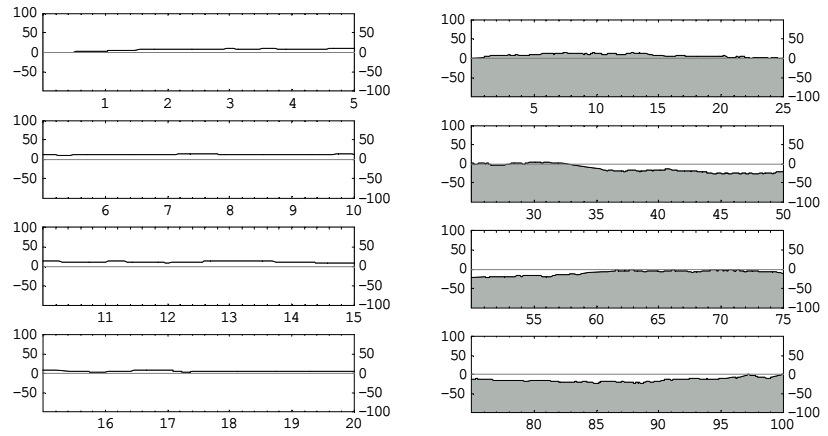

Rys. 4. Droga asfaltobetonowa bardzo dobrej jakości

Na rys. 3 i 4 przedstawiono wybrane przykłady wygenerowanych nierówności $w(s)[\mathrm{mm}]$ po długości $s[\mathrm{~m}]$ dla dróg różnej jakości.

\section{Opis metody szybkiej transformaty Fouriera}

Druga $\mathrm{z}$ prezentowanych metod polega na wykorzystaniu algorytmu FFT tzw. szybkiej transformaty Fouriera i funkcji gęstości widmowej $S_{u}(\omega)$.

Na podstawie gęstości widmowej $S_{u}(\omega)$ generowany jest ciąg dyskretnych wartości funkcji:

$$
u_{m}, m=0, \ldots, N-1 \text {. }
$$

Do obliczeń generacyjnych przyjmuje się funkcję gęstości widmowej $S_{u}(\omega)$ określoną zwykle w wyniku pomiarów, z częstością graniczną analizy $\omega_{m}$.

$$
S_{u}(\omega)= \begin{cases}S_{u}(\omega) & , \omega \in\left[0, \omega_{m}\right] \\ 0 & , \omega>\omega_{m}\end{cases}
$$

gdzie:

$$
\omega \text { - częstość [rad/s] }
$$

Z uwagi, iż aparatura pomiarowa zwykle wyskalowana jest $w$ hercach, zamiast częstości zamiennie stosuje się częstotliwość $v[\mathrm{~Hz}]$ :

$$
v=\omega / 2 \pi
$$


W zależności od tego, czy generowana jest realizacja przemieszczeń $u(t)$ czy przyspieszeń $u_{a}(t)$, posługujemy się odpowiednio funkcją gęstości widmowej przemieszczeń $S_{u}(\omega)$ albo przyspieszeń $S_{a}(\omega)$, które wiąże zależność:

$$
S_{a}(\omega)=\omega^{4} \cdot S_{u}(\omega)
$$

Funkcję gęstości widmowej $S_{u}(\omega)$, poddaje się operacji kwantowania $\mathrm{z}$ krokiem $\Delta \omega$ tak dobranym, aby otrzymać ciagg wartości:

$$
S_{k}, k=0, \ldots, N-1
$$

Ciag ten traktowany jest jako estymator pozwalajacy na obliczenie przybliżonego modułu dyskretnej transformaty Fouriera funkcji $u(t)$ :

$$
|D(k)|=\left(\frac{\pi}{N \Delta t} S_{k}\right)^{0,5}
$$

gdzie:

$\Delta t-$ krok czasowy funkcji,

$N \Delta t=T-$ długość otrzymanej realizacji procesu.

Dyskretna transformata $D(k)$ funkcji $u(t)$ wyrażona wzorem:

$$
D(k)=\frac{1}{N} \sum_{m=0}^{N-1} u(m) \cdot e^{-i k m \frac{2 \pi}{N}}
$$

zapisywana jest symbolicznie:

$$
D(k)=D F T[u(m)]
$$

Częstotliwość $v$ nie występuje jawnie w dyskretnej transformacie, ale każdej wartości $k$ odpowiada częstotliwość:

$$
v_{k}=k \cdot \Delta v=k \cdot \frac{1}{T}=k \cdot \frac{1}{N \Delta t}
$$

Odstęp czasu $\Delta t$ między próbkami jest ściśle związany z graniczną częstotliwością:

$$
v_{m}=\frac{\omega_{m}}{2 \pi}
$$

warunkiem Nyquista:

$$
\Delta t>\frac{1}{2 \cdot v_{m}}
$$

Wprowadzając pojęcie częstotliwości próbkowania:

$$
v_{p}=\frac{1}{\Delta t}
$$

Warunek Nyquista należy interpretować w ten sposób, że częstotliwość próbkowania $v_{p}$ powinna być większa od dwukrotnej wartości częstotliwości granicznej przebiegu:

$$
v_{p}>2 \cdot v_{m}
$$

co jednocześnie oznacza, że na składową harmoniczną przebiegu $u(t)$ o największej częstotliwości powinny przypadać więcej niż dwie próbki.

Dla pełnego określenia dyskretnej transformaty DFT konieczna jest znajomość argumentu:

$$
\alpha(k), k=0, \ldots, N-1 .
$$

Przyjmuje się go za zmienną losową o rozkładzie równomiernym z przedziału $[-\pi, \pi]$.

Aby otrzymać funkcję $u(t)$ dla dyskretnych punktów czasu:

$$
t_{m}=m \cdot \Delta t
$$

wystarczy dokonać obliczenia odwrotnej dyskretnej transformaty Fouriera IDFT postaci:

$$
u(m)=\sum_{k=0}^{N-1} D(k) e^{\left[\frac{[2 k m m}{N}+\alpha(k)\right]}
$$

gdzie: $m=0, \ldots, N-1$

W pracy wykorzystano algorytm szybkiej transformaty FFT [1], pozwalający niezwykle szybko wyznaczyć komplet dyskretnych transformat ciagu $u(m)$, gdy $N$ jest potegą liczby 2 .

Dyskretna transformata Fouriera jest funkcją okresową w dziedzinie częstotliwości, o okresie wynoszącym $v_{p}$. Dyskretną transformatę ciągu składającego się z $N$ próbek o wartościach rzeczywistych można obliczyć za pomocą transformaty dwóch o połowę krótszych próbek, o indeksach parzystych i nieparzystych. Powyższa własność stanowi podstawę algorytmu szybkiej transformaty FFT. Właściwości szybkiej transformaty Fouriera można znaleźć m.in. w publikacjach $[1,2,5,6]$. Odpowiednio odwrotna, szybka dyskretna transformata jest funkcją okresowa, o okresie $T$ w dziedzinie czasu.

Poniżej zamieszczono przykłady realizacji procesów przypadkowych z użyciem opisanej metody szybkiej transformaty FFT.

W badaniach symulacyjnych wykorzystano funkcje gęstości widmowych przyspieszeń drgań podłogi w kabinach maszynistów - operatorów pojazdów szynowych, uzyskane w pracy [3] na podstawie pomiarów w rzeczywistych warunkach ruchowych, dla różnych rodzajów pojazdów.

Przykładowe wykresy funkcji gęstości widmowych przyspieszeń drgań w pojazdach przedstawiono poniżej na rys. 5 i 6.

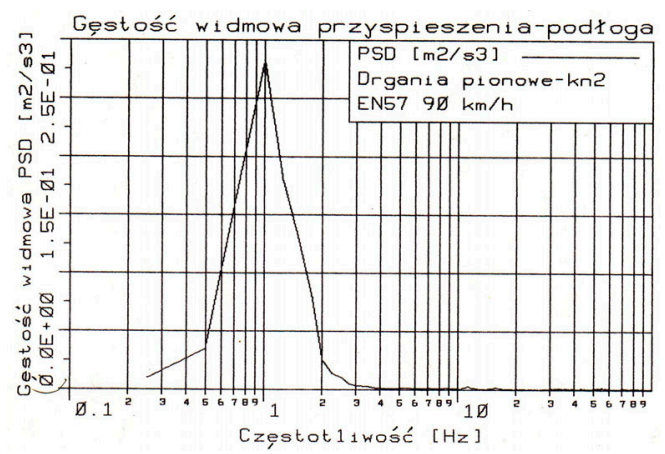

Rys. 5. Gęstość widmowa przyspieszeń drgań w elektrycznym zespole trakcyjnym 


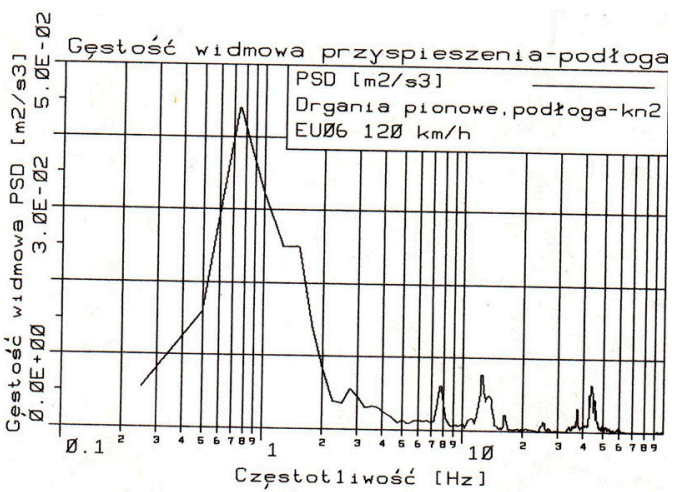

Rys. 6. Gęstość widmowa przyspieszeń drgań w lokomotywie elektrycznej

Zdyskretyzowane funkcje gęstości widmowych umożliwiają generowanie procesu drgań, przemieszczeń i przyspieszeń drgań podłogi $\mathrm{w}$ kabinach pojazdów. Zakłada się zwykle, że proces drganiowy ma tu charakter stacjonarny i ergodyczny. W badaniach symulacyjnych generowano opisaną wyżej metodą FFT drgania podłogi, stanowiące wymuszenie kinematyczne dla układu siedzisko - operator pojazdu.

Otrzymane realizacje drgań podłogi w pojeździe umożliwiają badania symulacyjne różnych konstrukcji foteli maszynistów, z pasywnymi i aktywnymi układami wibroizolacji. W badaniach wykorzystuje się też złożone modele siedzącego człowieka - operatora pojazdu [3].

$\mathrm{Na}$ rys. 7 i 8 przedstawiono przykłady realizacji przemieszczeń i przyspieszeń podłogi oraz siedziska maszynisty z pneumatycznym aktywnym układem wibroizolacji w uniwersalnej lokomotywie elektrycznej.

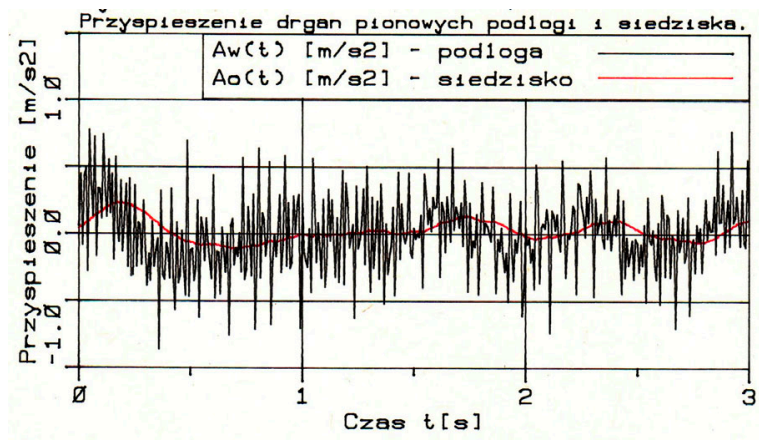

Rys. 7. Przyspieszenie drgań podłogi i fotela z aktywnym układem wibroizolacji

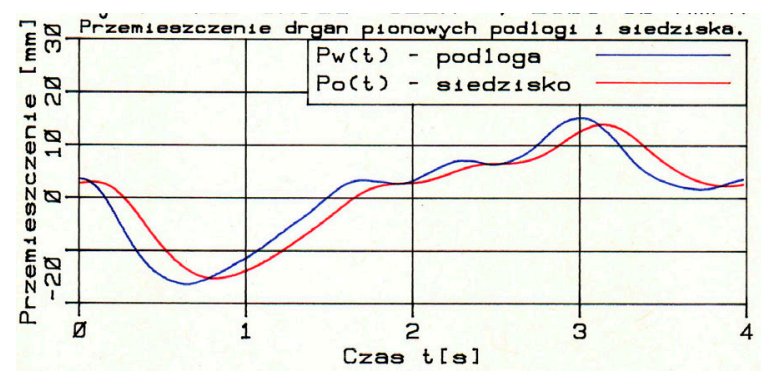

Rys. 8. Przemieszczenia drgań podłogi i fotela z aktywnym układem wibroizolacji

\section{Wnioski}

Zaletą pierwszej prezentowanej metody jest to, że kolejne generowane odcinki realizacji omawianych procesów spełniają warunki ciagłości tych realizacji i ich pochodnych.

Zaletą drugiej metody opartej na szybkiej transformacie Fouriera jest szybkość obliczeniowa. Ma to szczególne znaczenie $\mathrm{w}$ badaniach symulacyjnych złożonych układów, gdzie ta sama programowa procedura prostej transformaty FFT i jej transformaty odwrotnej IFFT może być wykorzystana do obliczania odpowiedzi układu na różne rodzaje wymuszeń. Wadą tej metody jest okresowość uzyskanych realizacji w dziedzinie czasu. Nie jest w tej metodzie możliwe „sklejanie” kolejnych odcinków realizacji z ciagłością procesu i jej pochodnych.

Przedstawione metody umożliwiają komputerowe modelowanie procesów przypadkowych niezbędnych w analizie dynamicznej pojazdów lądowych.

\section{Literatura}

[1] CooleyJ.W., Tukey J.W., An Algorithm for Machine Computation of Complex Fourier Series, Mathematics of Computation 19, April 1965.

[2] Kamiński E., Pokorski J., Dynamika zawieszeń $i$ układów napędowych pojazdów samochodowych, WKit, Warszawa 1983.

[3] Kis i e lews ki P., Analiza i synteza układów wibroizolacji siedzisk maszynistów, operatorów lokomotyw, Rozprawa doktorska, AGH, Kraków 1992.

[4] Mitschke M., Dynamika samochodu, WKiE, Warszawa 1989.

[5] Rao K.R., Ahmed N., Orthogonal Transforms for Digital Signal Processing, Springer-Verlag, BerinHeidelberg-New York 1975.

[6] Sobczyk K., Metody dynamiki statystycznej, PWN, Warszawa 1973. 